\title{
Trabecular microbypass as replacement therapy in pharmacologically controlled open-angle glaucoma patients
}

\author{
Implante de by-pass trabecular como alternativa aos colírios \\ em portadores de glaucoma de ângulo aberto controlados \\ com tratamento clínico
}

\author{
Ricardo Augusto Paletta Guedes' D, Daniela Marcelo Gravina', Vanessa Maria Paletta Guedes², Alfredo Chaoubah \\ 1. Universidade Federal de Juiz de Fora, Juiz de Fora, MG, Brazil. \\ 2. Instituto de Olhos Paletta Guedes, Juiz de Fora, MG, Brazil.
}

\begin{abstract}
I Purpose: To assess the outcomes of the trabecular bypass as replacement therapy for medications in pharmacologically controlled vs. pharmacologically uncontrolled open-angle glaucoma patients. Methods: This was a retrospective study of eyes treated with first- (iStent) or second-generation (iStent inject) trabecular bypass. Group 1 consisted of eyes with pharmacologically controlled intraocular pressure $<18 \mathrm{mmHg}$ and Group 2 consisted of eyes with pharmacologically controlled intraocular pressure $\geq 18 \mathrm{mmHg}$. The main outcomes measured were qualified (with or without medications) and unqualified or complete (without medications) success rates at different target intraocular pressures, mean reduction (\%) in medication use, and proportion of medication-free eyes. Results: The mean age was 70.4 years in Group $1(n=105)$ and 68.1 years in Group $2(n=65)$. Qualified success rates for intraocular pressure $<18 \mathrm{mmHg}$, intraocular pressure $<15 \mathrm{mmHg}$, and intraocular pressure $<12 \mathrm{mmHg}$ were similar between the groups (Group 1: 96.2\%, 88.6\%, and 32.4\%, respectively; Group 2: 93.8\%, 78.5\%, and $21.5 \%$, respectively; all $p>0.05)$. Complete success rates were significantly higher in Group 1 than in Group 2: for intraocular pressure $<18 \mathrm{mmHg}$ (76.2\% vs. $47.7 \%)$, intraocular pressure $<15 \mathrm{mmHg}(73.3 \%$ vs. $40.0 \%)$, and intraocular pressure $<12 \mathrm{mmHg}$ (14.3\% vs. $4.6 \%$ ). The mean reduction in medication use was higher in Group 1 than in Group 2. At the end of follow-up, $79.0 \%$ of eyes in Group 1 and $47.7 \%$ of eyes in Group 2 became medication-free. Conclusions: Both groups showed high qualified
\end{abstract}

Submitted for publication: January 15, 2021 Accepted for publication: October 7, 2021

Funding: This study received no specific financial support.

Disclosure of potential conflicts of interest: None of the authors have any potential conflicts of interest to disclose.

Corresponding author: Ricardo A. Paletta Guedes.

E-mail: palettaguedes@yahoo.com

Approved by the following research ethics committee: Santa Casa de Misericordia de Juiz de Fora (\#3.629.848) success rates, but eyes with baseline pharmacologically controlled intraocular pressure $<18 \mathrm{mmHg}$ showed higher complete success rates and greater chances of achieving no need for medications.

Keywords: Ophthalmologic surgical procedures; Cataract extraction; Glaucoma, open-angle; Glaucoma/therapy; Glaucoma/surgery

RESUMO I Objetivo: Avaliar os resultados dos implantes de by-pass trabecular como terapia de substituição aos colírios em pacientes com glaucoma de ângulo aberto controlados com medicação vs. não controlados com medicação. Métodos: Este foi um estudo retrospectivo de olhos submetidos a cirurgia de implante de by-pass trabecular de primeira (iStent) ou segunda geração (iStent inject). O Grupo 1 consistiu em olhos com pressão intraocular medicada $<18 \mathrm{mmHg}$ e o Grupo 2 consistiu em olhos com pressão intraocular medicada $\geq 18 \mathrm{mmHg}$. Os principais desfechos foram as taxas de sucesso relativo (com ou sem medicamentos) e completo (sem medicamentos) em diferentes pressões intraoculares-alvo, redução média (\%) no uso de medicamentos e proporção de olhos sem medicamentos. Resultados: A média de idade foi de 70,4 anos no Grupo 1 $(n=105)$ e 68,1 anos no Grupo $2(n=65)$. As taxas de sucesso relativo para pressão intraocular $<18 \mathrm{mmHg}$, pressão intraocular $<15$ mmHg e pressão intraocular $<12 \mathrm{mmHg}$ foram semelhantes entre os grupos (Grupo 1: 96,2\%, 88,6\% e 32,4\%, respectivamente; Grupo 2: 93,8\%, 78,5\% e 21,5\%, respectivamente; todos $p>0,05)$. As taxas de sucesso completo foram significativamente maiores no Grupo 1 do que no Grupo 2: pressão intraocular $<18 \mathrm{mmHg}(76,2 \%$ vs. 47,7\%); pressão intraocular < $15 \mathrm{mmHg}$ (73,3\% vs. $40 \%)$; pressão intraocular < $12 \mathrm{mmHg}(14,3 \%$ vs. $4,6 \%$ ). A redução média no uso de medicamentos foi maior no Grupo 1 do que no Grupo 2. Ao final do acompanhamento, 79,0\% dos olhos do Grupo 1 e 47,7\% dos olhos do Grupo 2 estavam livres medicamentos. Conclusões: Ambos os grupos 
mostraram altas taxas de sucesso relativo, mas olhos com pressão intraocular medicada pré-operatória $<18 \mathrm{mmHg}$ apresentaram taxas de sucesso completo mais elevadas, bem como maiores chances de se tornarem livres de medicamentos para glaucoma.

Descritores: Procedimentos cirúrgicos oftalmológicos; Extração de catarata; Glaucoma, ângulo aberto; Glaucoma/terapia; Glaucoma/cirurgia

\section{INTRODUCTION}

There are two major groups of microinvasive glaucoma surgery (MIGS) techniques, i.e., those aiming to achieve rehabilitation of the natural aqueous outflow pathway (trabecular ablation, trabecular bypass, or Schlemm's canal dilation) and those creating an artificial drainage pathway (subconjunctival or suprachoroidal drainage techniques), which should be reserved for eyes where the natural trabecular outflow system is no longer viable ${ }^{(1-4)}$.

The earlier the glaucoma stage is, the greater is the probability of a viable and functional posttrabecular outflow system ${ }^{(4-6)}$. Eyes that show a good response to intraocular pressure (IOP)-lowering medications or selective laser trabeculoplasty tend to have better viability of the natural aqueous outflow system ${ }^{(4-6)}$.

Trabecular microbypass devices, such as iStent and iStent inject, are used to create a direct passage through the trabecular meshwork, leading to communication between the anterior chamber and the posttrabecular structures $^{(3,7-10)}$.

In open-angle glaucoma, surgeries are often indicated when medication treatment or laser trabeculoplasty has failed. This is probably not the best scenario for trabecular microbypass surgeries, as a failure of noninvasive therapies can be an indirect predictor of poor viability of the posttrabecular outflow system ${ }^{(11)}$.

We hypothesized that the best outcomes with trabecular bypass surgeries would be achieved when IOP is still under control with topical medications, as this is a sign of a viable and still functioning posttrabecular outflow system.

To the best of our knowledge, no clinical evidence is available regarding differences in trabecular microbypass surgery outcomes based on IOP control under glaucoma medications before surgery. Konopinska et al. prospectively assessed the success of combined cataract and first-generation trabecular microbypass procedure in eyes with a baseline IOP (after washout) above or below $26 \mathrm{mmHg}$ without pharmacological therapy. They found that eyes with $\mathrm{lOP}<26 \mathrm{mmHg}$ without pharmacological therapy achieved higher rates of success ${ }^{(12)}$.

This study investigated the outcomes of first- and second-generation trabecular microbypass devices as replacement therapy to medications in pharmacologically controlled (IOP $<18 \mathrm{mmHg}$ ) compared to pharmacologically uncontrolled (IOP $\geq 18 \mathrm{mmHg}$ ) open-angle glaucoma patients.

\section{METHODS}

This retrospective study examined eyes treated with either iStent or iStent inject in a single center.

The inclusion criteria were first- or second-generation trabecular bypass implant surgery, age $>18$ years, open-angle glaucoma (primary open-angle glaucoma, pigmentary glaucoma, or pseudoexfoliative glaucoma), glaucoma-only or combined with cataract surgery, at least 6 months of follow-up, and no ocular comorbidity. We included only one eye per patient; hence, if both eyes of the same patient were eligible, we randomly selected one of them.

The exclusion criteria were missing data in the records, all other types of glaucoma, including normal-tension glaucoma, and ocular comorbidity. We also excluded the first 10 cases of iStent implantation and the first five cases of iStent inject implantation because they were considered part of the learning curve. All surgeries were performed by the same surgeon in a single site.

In addition to the demographic and clinical data (age, sex, race, type of glaucoma, and glaucoma stage), we evaluated the mean follow-up time, changes in IOP, number of glaucoma medications, and visual acuity from the preoperative period to the end of follow-up.

The glaucoma stage was determined according to the Hodapp-Parrish-Anderson criteria based on the mean deviation (MD) of Humphrey computerized perimetry. Eyes were categorized as having mild (MD better than $-6 \mathrm{~dB}$ ), moderate (MD between $-6.00 \mathrm{~dB}$ and $-12.00 \mathrm{~dB}$ ), and advanced (MD worse than $-12.00 \mathrm{~dB}$ ) glaucoma ${ }^{(13)}$.

The study population was divided into two groups: Group 1 (pharmacologically controlled IOP; baseline medicated $\mathrm{lOP}<18 \mathrm{mmHg}$ ) and Group 2 (pharmacologically uncontrolled IOP; baseline medicated IOP $\geq 18 \mathrm{mmHg}$ ). The main outcomes measured were reduction of the mean IOP (\%), reduction of the mean number of medications (\%), the proportion of medication-free eyes at the end of follow-up, qualified success rates (with adjunctive glaucoma medications as needed) at 
different IOP levels (IOP $<18 \mathrm{mmHg},<15 \mathrm{mmHg}$, and $<12 \mathrm{mmHg}$ ), unqualified or complete success rates (without adjunctive glaucoma medications) at different IOP levels (IOP < $18 \mathrm{mmHg}$, $<15 \mathrm{mmHg}$, and $<12 \mathrm{mmHg}$ ), and probability of success determined by survival analyses based on two criteria (IOP $<18 \mathrm{mmHg}$ and IOP $<15 \mathrm{mmHg}$ ). We also evaluated the numbers of intra- and postoperative complications.

All numerical variables were tested for normality of their distribution through the Kolmogorov-Smirnov test. Student's $t$ test was used for comparisons of variables with a normal distribution. Non-parametric tests (Kruskal-Wallis or Mann-Whitney test) were used for variables with a non-normal distribution. The chi-square test was used for analyses of categorical variables.

All statistical analyses were performed using IBM SPSS Statistics 25 (IBM Corp., Armonk, NY, USA). In all analyses, $p<0.05$ indicated statistical significance.

This study was performed in accordance with the Declaration of Helsinki and was approved by the Ethics Committee of the Santa Casa de Misericordia de Juiz de Fora (CAAE: 21327319.5.0000.5139).

\section{RESULTS}

The study population consisted of 170 eyes with a mean \pm standard deviation (SD) follow-up time of 20.1 \pm 8.6 months (range 6-38).

Group 1 and Group 2 consisted of 105 eyes (61.8\%) and 65 eyes $(38.2 \%)$, respectively. The mean ( \pm SD) follow-up periods were $21.2( \pm 8.2)$ months and 18.4 $( \pm 9.1)$ months, respectively $(p=0.048)$. Table 1 presents the baseline characteristics of the groups. The baseline number of medications, glaucoma stage, and type of surgery were statistically different between groups and as these variables could have influenced our findings, we performed additional analyses for their control.

\section{IOP results}

At the end of the follow-up, the mean IOP reduction (percentage) was 6.3\% in Group 1 and 29.1\% in Group 2 (between-group comparison, $\mathrm{p}<0.001$ ). Figure 1 shows the changes in IOP for each group. Table 2 shows the changes in the mean IOP and mean number of glaucoma medications from baseline to 24 months and the sample size for each group during follow-up. Success rates according to IOP are given in table 3 .

We also performed survival analyses based on the Kaplan-Meier survival curves (Figure 2). The mean survival periods were significantly higher in Group 1 at both IOP $<18 \mathrm{mmHg}$ and IOP $<15 \mathrm{mmHg}$ with no medications. The probabilities of success at IOP $<18 \mathrm{mmHg}$ without medications were $72.4 \%$ and $36.9 \%$ for Groups 1 and 2, respectively. In addition, considering IOP $<15 \mathrm{mmHg}$ with no medications, the probabilities of success were 49.5\% for Group 1 and 20.0\% for Group 2.

Table 1. Baseline characteristics of each group

\begin{tabular}{|c|c|c|c|}
\hline Characteristics & $\begin{array}{c}\text { Group } 1 \\
n=105\end{array}$ & $\begin{array}{c}\text { Group } 2 \\
\mathrm{n}=65\end{array}$ & p-value \\
\hline Age (mean $\pm S D$ ), years & $70.4 \pm 8.9$ & $68.1 \pm 10.5$ & $0.132 a$ \\
\hline $\begin{array}{l}\text { Baseline IOP (mean } \pm \\
\mathrm{SD}), \mathrm{mmHg}\end{array}$ & $14.3 \pm 2.0$ & $19.9 \pm 1.9$ & $<0.001 \mathrm{a}$ \\
\hline $\begin{array}{l}\text { Baseline number of } \\
\text { medications (mean } \pm \text { SD) }\end{array}$ & $1.9 \pm 0.9$ & $2.3 \pm 1.0$ & $0.004 a$ \\
\hline \multicolumn{4}{|l|}{ Race } \\
\hline Caucasian & $84.8 \%$ & $83.1 \%$ & $0.746 b$ \\
\hline African descent or mixed & $15.2 \%$ & $16.9 \%$ & \\
\hline \multicolumn{4}{|l|}{ Sex } \\
\hline Male & $39.0 \%$ & $44.6 \%$ & $0.289 \mathrm{~b}$ \\
\hline Female & $61.0 \%$ & $55.4 \%$ & \\
\hline \multicolumn{4}{|l|}{ Glaucoma stage } \\
\hline Mild & $87.6 \%$ & $66.2 \%$ & $<0.001 b$ \\
\hline Moderate & $5.7 \%$ & $27.7 \%$ & \\
\hline Advanced & $6.7 \%$ & $6.2 \%$ & \\
\hline \multicolumn{4}{|l|}{ Laterality } \\
\hline OD & $51.4 \%$ & $53.8 \%$ & $0.441 \mathrm{~b}$ \\
\hline OS & $48.6 \%$ & $46.2 \%$ & \\
\hline Type of glaucoma & $85.7 \%$ & $83.1 \%$ & $0.399 \mathrm{~b}$ \\
\hline POAG & $14.3 \%$ & $16.9 \%$ & \\
\hline \multicolumn{4}{|l|}{ Other OAG } \\
\hline Baseline visual acuity & $61.0 \%$ & $67.7 \%$ & $0.526 \mathrm{~b}$ \\
\hline $20 / 30$ or better & $34.3 \%$ & $26.2 \%$ & \\
\hline $20 / 40$ to $20 / 100$ & $4.8 \%$ & $6.2 \%$ & \\
\hline \multicolumn{4}{|l|}{$20 / 200$ or worse } \\
\hline Type of surgery & $87.6 \%$ & $67.7 \%$ & $0.002 b$ \\
\hline $\begin{array}{l}\text { Combined with } \\
\text { cataract }\end{array}$ & $12.4 \%$ & $32.3 \%$ & \\
\hline \multicolumn{4}{|l|}{ Standalone } \\
\hline Type of bypass & $34.3 \%$ & $23.1 \%$ & $0.083 b$ \\
\hline iStent & $65.7 \%$ & $76.9 \%$ & \\
\hline iStent inject & & & \\
\hline
\end{tabular}




\section{Reduction of medications}

At the end of the follow-up, the mean reduction in the number of medications was $84.2 \%$ in Group 1 and $60.9 \%$ in Grroup 2 (between-group comparison, $\mathrm{p}=0.002)$.

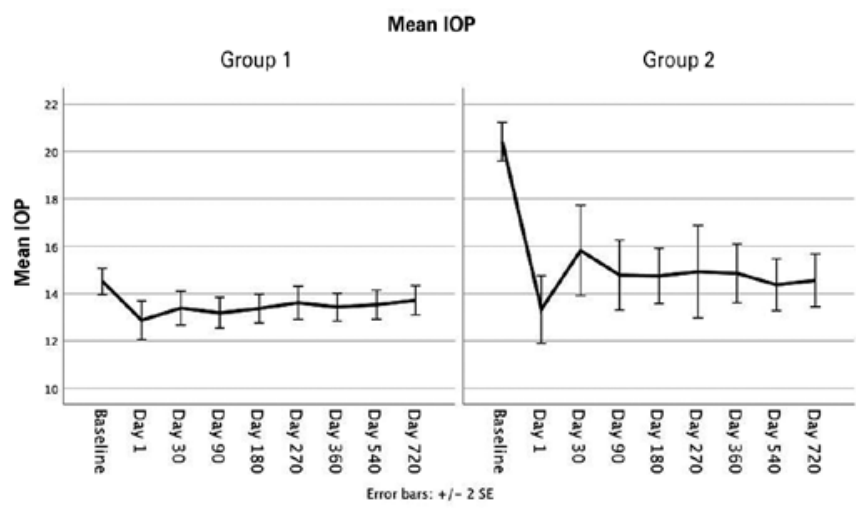

$\mathrm{IOP}=$ intraocular pressure.

Figure 1. Changes in IOP from baseline to the end of follow-up for Group 1 (baseline IOP $<18 \mathrm{mmHg}$ under pharmacological treatment) and Group 2 (baseline IOP $\geq 18 \mathrm{mmHg}$ under pharmacological treatment).
Preoperatively, $58.1 \%$ and $78.5 \%$ of eyes in Groups 1 and 2 were receiving two or more glaucoma medications. At the end of follow-up (mean: 20.1 months), $79.0 \%$ of eyes in Group 1 and $47.7 \%$ in Group 2 became medication-free.

Table 2 summarizes the changes in the mean number of medications per eye in each group. The difference in the postoperative mean number of medications vs. baseline was statistically significant at all time points $(p<0.001)$ for both groups.

Figure 3 shows the final number of glaucoma medications per eye at the end of follow-up (mean: 20.1 months).

\section{Visual acuity and safety results}

Overall, $61 \%$ and $67.7 \%$ of eyes in Groups 1 and 2 $(p=0.526)$, respectively, showed visual acuity of $20 / 30$ or better at baseline whereas $90.5 \%$ and $96.9 \%$ of eyes in Groups 1 and 2, respectively, showed the same visual acuity level at the end of follow-up $(p=0.263)$.

Table 2. Evolution of mean IOP and mean number of glaucoma medications from baseline to month 24

\begin{tabular}{|c|c|c|c|c|c|c|}
\hline \multirow[b]{2}{*}{ Time point } & \multicolumn{2}{|c|}{ Group 1} & \multicolumn{2}{|c|}{ Group 2} & \multirow{2}{*}{$\begin{array}{c}\text { Comparisons between } \\
\text { groups for } \mathrm{IOP}^{\mathrm{a}}\end{array}$} & \multirow{2}{*}{$\begin{array}{l}\text { Comparisons between } \\
\text { groups for Meds }\end{array}$} \\
\hline & IOP (mmHg) & Meds & IOP (mmHg) & Meds & & \\
\hline \multirow[t]{2}{*}{ Baseline } & 14.3 & 1.9 & 19.9 & 2.3 & $<0.001$ & 0.004 \\
\hline & \multicolumn{2}{|c|}{$\mathrm{n}=105$} & \multicolumn{2}{|c|}{$\mathrm{n}=65$} & & \\
\hline \multirow[t]{2}{*}{ Day 1} & $13.3^{*}$ & $0.1^{*}$ & $12.9 *$ & $0.2^{*}$ & 0.523 & 0.787 \\
\hline & \multicolumn{2}{|c|}{$\mathrm{n}=105$} & \multicolumn{2}{|c|}{$\mathrm{n}=65$} & & \\
\hline \multirow[t]{2}{*}{ Day 15} & 14.0 & $0.2^{*}$ & $16.4^{*}$ & $0.5^{*}$ & 0.002 & 0.005 \\
\hline & \multicolumn{2}{|c|}{$\mathrm{n}=105$} & \multicolumn{2}{|c|}{$n=65$} & & \\
\hline \multirow[t]{2}{*}{ Day 30} & $13.3^{*}$ & $0.2^{*}$ & $15.2^{*}$ & $0.8^{*}$ & 0.001 & $<0.001$ \\
\hline & \multicolumn{2}{|c|}{$\mathrm{n}=105$} & \multicolumn{2}{|c|}{$n=65$} & & \\
\hline \multirow[t]{2}{*}{ Day 90} & $13.2^{*}$ & $0.2^{*}$ & $13.8^{*}$ & $0.8^{*}$ & 0.238 & $<0.001$ \\
\hline & \multicolumn{2}{|c|}{$\mathrm{n}=105$} & \multicolumn{2}{|c|}{$n=65$} & & \\
\hline \multirow[t]{2}{*}{ Day 180} & $13.3^{*}$ & $0.3^{*}$ & $14.0^{*}$ & $0.8^{*}$ & 0.090 & $<0.001$ \\
\hline & \multicolumn{2}{|c|}{$\mathrm{n}=105$} & \multicolumn{2}{|c|}{$n=65$} & & \\
\hline \multirow[t]{2}{*}{ Day 270} & $13.6^{*}$ & $0.3^{*}$ & $14.1^{*}$ & $0.8^{*}$ & 0.354 & $<0.001$ \\
\hline & \multicolumn{2}{|c|}{$\mathrm{n}=98$} & \multicolumn{2}{|c|}{$n=56$} & & \\
\hline \multirow[t]{2}{*}{ Day 360} & $13.6^{*}$ & $0.3^{*}$ & $14.5^{*}$ & $0.9^{*}$ & 0.056 & $<0.001$ \\
\hline & \multicolumn{2}{|c|}{$n=89$} & \multicolumn{2}{|c|}{$n=52$} & & \\
\hline \multirow[t]{2}{*}{ Day 540} & $13.7^{*}$ & $0.3^{*}$ & $14.1^{*}$ & $0.9 *$ & 0.266 & 0.002 \\
\hline & \multicolumn{2}{|c|}{$n=78$} & \multicolumn{2}{|c|}{$n=33$} & & \\
\hline \multirow[t]{2}{*}{ Day 720} & $13.7^{*}$ & $0.3^{*}$ & $14.6^{*}$ & $0.9^{*}$ & 0.154 & 0.007 \\
\hline & \multicolumn{2}{|c|}{$n=49$} & \multicolumn{2}{|c|}{$n=27$} & & \\
\hline
\end{tabular}

${ }^{*} \mathrm{p}<0.05$ vs. baseline (paired-samples Student's $t$ test).

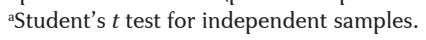

IOP, intraocular pressure; Meds: number of glaucoma medications per eye. 
Table 3. Qualified (with glaucoma medications) and unqualified (without glaucoma medications) success rates for different IOP levels

\begin{tabular}{lcccc}
\hline Success criteria & & $\begin{array}{c}\text { Group 1 } \\
\mathbf{n = 1 0 5}\end{array}$ & $\begin{array}{c}\text { Group 2 } \\
\mathbf{n = 6 5}\end{array}$ & p-value \\
\hline \multirow{2}{*}{ IOP $<18 \mathrm{mmHg}$} & Qualified & $96.2 \%$ & $93.8 \%$ & 0.363 \\
& Unqualified & $76.2 \%$ & $47.7 \%$ & $<0.001$ \\
\multirow{2}{*}{$\mathrm{OP}<15 \mathrm{mmHg}$} & Qualified & $88.6 \%$ & $78.5 \%$ & 0.061 \\
& Unqualified & $73.3 \%$ & $40.0 \%$ & $<0.001$ \\
\multirow{2}{*}{$\mathrm{OP}<12 \mathrm{mmHg}$} & Qualified & $32.4 \%$ & $21.5 \%$ & 0.087 \\
& Unqualified & $14.3 \%$ & $4.6 \%$ & 0.037 \\
\hline
\end{tabular}

$\mathrm{IOP}=$ Intraocular pressure.
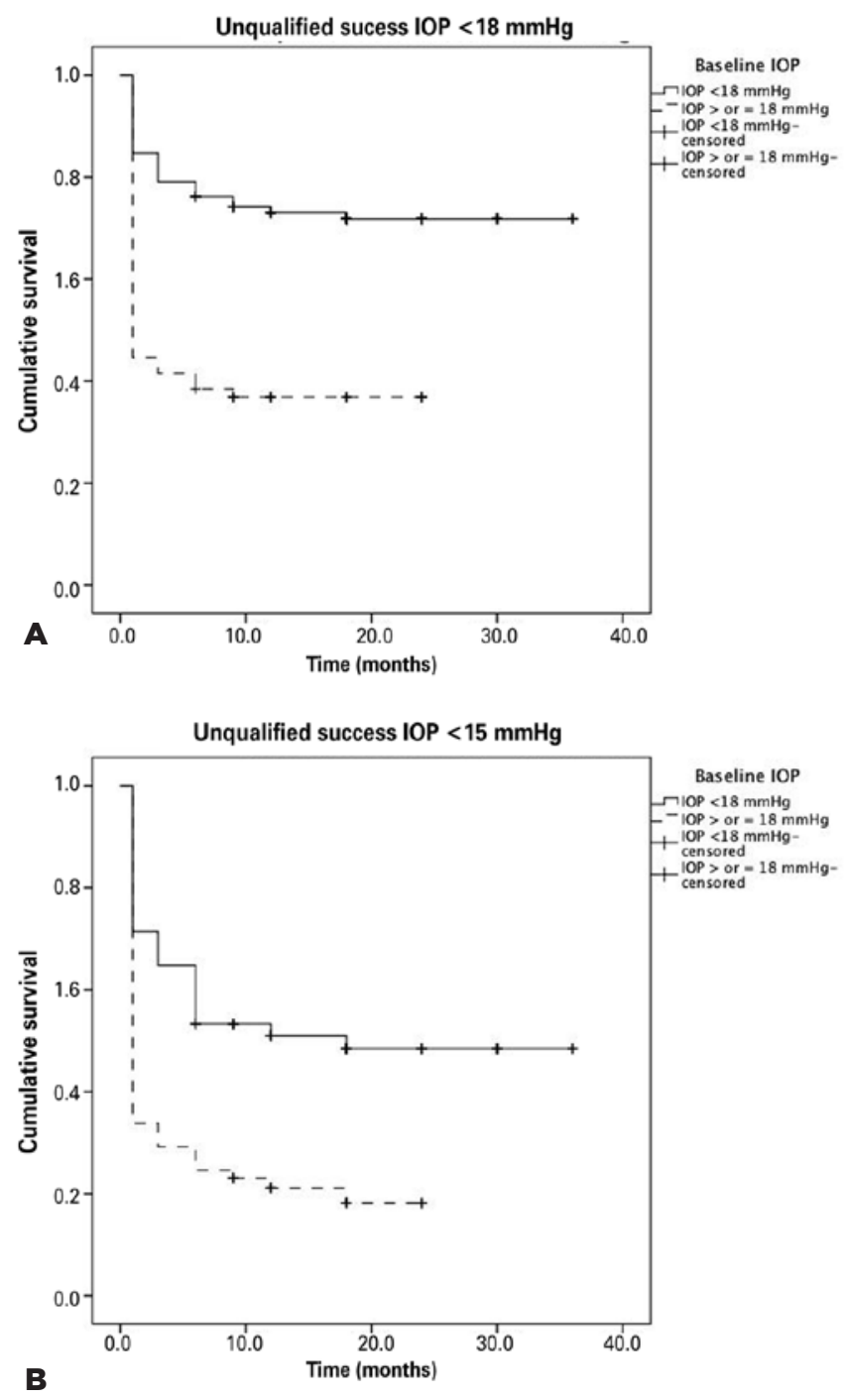

Figure 2. Kaplan-Meier survival curves for complete success for both groups: (A) IOP<18 mmHg and (B) $1 O P<15 \mathrm{mmHg}$.
Both groups showed a high safety profile. Most patients (96.2\% in Group 1 and 98.5\% in Group 2) did not present any procedure-related complications intraoperatively $(p=0.626)$. There were three cases $(2.9 \%)$ of intraoperative excessive blood reflux in Group 1 and one case (1.5\%) in Group 2. There was one case of iStent misplacement in group $1(1.0 \%)$ and none in Group 2 $(\mathrm{p}=0.626)$.

Complications in the postoperative period were also rare. Most eyes in both groups did not have complications (98.1\% of eyes in Group 1 and 96.9\% in Group 2, $\mathrm{p}=0.438)$.

In Group 1, one eye showed peripheral anterior synechia occluding the internal ostia of the iStent, which was corrected by Nd:YAG laser iridotomy. In this group, one eye presented with uncontrolled IOP, requiring surgery during the follow-up. The patient could not tolerate any ocular hypotensive agents due to ocular allergy, and the iStent was not sufficient to control IOP.

In Group 2, two eyes required surgery due to uncontrolled IOP. These eyes developed steroid-induced IOP spikes. Patients had to be kept on systemic steroids for pulmonary and rheumatological diseases. These eyes were excluded from the analyses of IOP, medications, and success rates.

\section{Controlling for possible confounding variables}

We performed univariate analysis for each possible confounding variable (baseline number of medications, glaucoma stage, and type of surgery) and a multivariate Cox regression survival analysis. Although Groups 1 and 2 were well-balanced according to the type of bypass (iStent vs. iStent inject), we decided to include this variable in this analysis.

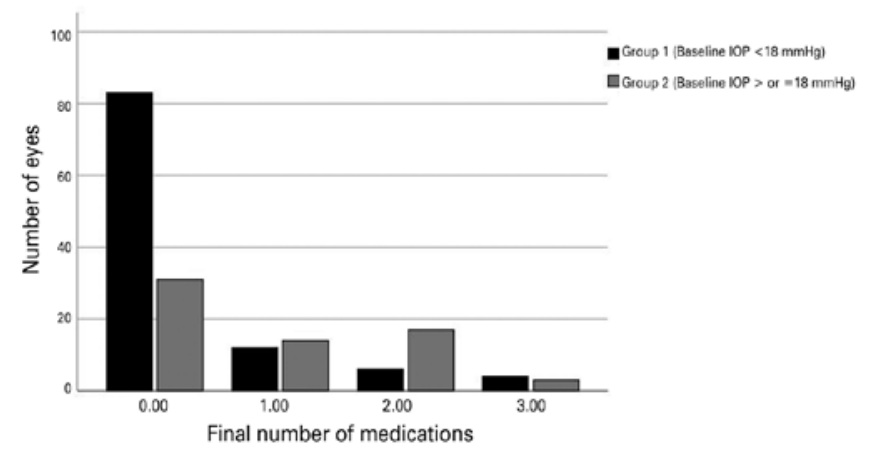

Figure 3. Proportion of eyes according to the number of glaucoma medications at the final time point for both groups. 


\section{Baseline number of medications}

The mean number of baseline glaucoma medications was significantly greater in Group 2 than Group $1(2.3$ vs. 1.9 , respectively, $p=0.004)$. We excluded eyes receiving one medication at baseline from the analysis and only considered eyes with two or more medications at baseline in each group. Then, the mean number of medications was similar between the groups, along with the proportions of eyes on two, three, or four medications at baseline. Follow-up periods were also similar. However, the final mean number of medications was significantly higher in Group 2 than in Group 1 (1.2 vs. 0.5 medications, respectively, $\mathrm{p}=0.001)$, as was the number of eyes with no medications at the end of follow-up (67.2\% vs. $33.3 \%$, respectively, $\mathrm{p}<0.001$ ).

In addition, analyses of qualified and complete success rates confirmed the outcomes described previously. The groups had similar qualified success rates but Group 1 had a higher complete success rate.

\section{Glaucoma stage}

Group 2 had a higher proportion of eyes with moderate glaucoma, and Group 1 had more eyes with mild glaucoma. We controlled for the glaucoma stage by evaluating outcomes considering only patients with mild glaucoma. In all, 92 were included in Group 1 and 43 in Group 2, and $84.8 \%$ and $60.5 \%$ of eyes, respectively, were medication-free at the end of follow-up. Qualified success rates were similar between the groups, however, eyes in Group 1 had a higher complete success rate, confirming our previous results.

\section{Type of surgery (combined vs. standalone)}

The results did not change when we controlled for the type of surgery. When we included only combined surgeries, more eyes were medication-free at the end of follow-up in Group 1 than in Group 2 (85.9\% vs. 56.8\%, respectively, $p<0.001)$. There were no differences between the two groups in qualified success rates whereas complete success rates were significantly higher in
Group 1.

Type of trabecular microbypass implant (iStent vs. iStent inject)

Considering eyes treated with iStent inject only, Groups $1(n=69)$ and $2(n=50)$ were similar according to age, race, baseline number of medications, sex, laterality, glaucoma type, type of surgery, and follow-up period. Again, the qualified success rates did not differ between the groups whereas complete success rates were significantly higher in Group 1. A significantly greater number of eyes treated with iStent inject were not receiving medications at the end of follow-up in Group 1. The percentage of eyes with IOP reduction was greater in Group 2 while the percentage of eyes with a reduction in the number of medications was higher in Group 1.

\section{Multivariate Cox regression survival analysis}

We considered $\mathrm{IOP}<18 \mathrm{mmHg}$ without pharmacological treatment as a dependent variable for the regression model. All possible confounding or independent variables were included. The following independent variables were tested in the model: age, race, sex, laterality, baseline visual acuity, baseline number of medications, glaucoma stage, intra- and postoperative complications, type of surgery, and type of trabecular bypass (iStent or iStent inject). A significance of $95 \%$ was necessary for the variable to remain in the model.

Four steps were necessary until the final model was generated. Multivariate analysis confirmed baseline $\mathrm{IOP}<18 \mathrm{mmHg}$ as a strong predictor of unqualified success, along with combined surgery and use of iStent inject. We present the regression results as well as their interpretation in table 4.

\section{DISCUSSION}

The groups had similar qualified success rates for different IOP levels. However, medically controlled eyes at baseline (medicated IOP $<18 \mathrm{mmHg}$ ) showed consistently higher rates of medication-free outcomes. Hence, trabecular microbypass is useful and effective for

Table 4. Multivariate Cox regression survival analysis

\begin{tabular}{|c|c|c|c|}
\hline Variable & Significance & $\operatorname{Exp}(\beta)$ & Interpretation \\
\hline Baseline medicated IOP $<18 \mathrm{mmHg}$ & 0.026 & 1.636 & Presence of this variable is associated with $64 \%$ higher chance of achieving unqualified success \\
\hline Combined Surgery & 0.001 & 2.287 & Presence of this variable is associated with $1.3 x$ higher chance of achieving unqualified success \\
\hline iStent inject & 0.034 & 1.635 & Presence of this variable is associated with $64 \%$ higher chance of achieving unqualified success \\
\hline
\end{tabular}

Final model (Step 4); backward stepwise method (likelihood ratio) 
both situations. However, there is a greater likelihood of achieving a medication-free outcome for eyes with a baseline medicated IOP $<18 \mathrm{mmHg}$. Therefore, for such eyes, trabecular stents are a very useful and effective tool as replacement therapy for medications.

Survival analyses showed that eyes in Group 1 remained medication-free significantly longer with a higher probability of success than eyes in Group 2. The chance of achieving no need for glaucoma medications was much lower at baseline IOP $\geq 18 \mathrm{mmHg}$ under pharmacological treatment (Group 2), demonstrating that posttrabecular status is not the same as for eyes in Group 1. Trabecular stenting is still valuable, as all eyes achieved good success rates, although with the need for adjunctive use of glaucoma medications. These results suggest that stents can rehabilitate posttrabecular outflow to a certain degree. This may be because trabecular stents can rehabilitate the trabecular pathway in the inferonasal quadrant, but in eyes with a more advanced trabecular disease, rehabilitating only one quadrant helps but may not be enough to control IOP without the need for glaucoma medications.

Our results suggest two distinctive goals for trabecular surgery in the two study groups. For patients with baseline IOP $<18 \mathrm{mmHg}$ under pharmacological treatment, the goal of surgery may be very effective IOP control and no need for medications. Conversely, in patients with baseline IOP $\geq 18 \mathrm{mmHg}$ under pharmacological treatment, the main goal is to reduce IOP and patients should be advised about the greater probability of requiring some glaucoma medications after treatment.

The observed reductions in IOP are consistent with other studies regarding iStent and iStent inject ${ }^{(14-17)}$. We found that IOP decreased by a mean of $16.5 \%$ for the whole cohort, which included both pharmacologically controlled and uncontrolled eyes. Using a baseline IOP cutoff point of $18 \mathrm{mmHg}$ to separate controlled from uncontrolled eyes under pharmacological therapy, we found that the percentage of eyes that achieved IOP reduction was higher in those with higher (IOP $\geq 18 \mathrm{mmHg}$ under pharmacological treatment) than lower baseline IOP ( $29.1 \%$ vs. $6.3 \%$, respectively), consistent with Ferguson et al. ${ }^{(18)}$.r The higher is the baseline IOP, the higher is the percentage reduction in IOP. Therefore, there is a floor effect on the capacity of trabecular bypass for IOP reduction, which is the posttrabecular resistance to aqueous outflow. Regardless of the baseline IOP, there is always a greater chance of achieving a low to mid-teen final IOP value. If the eyes already have IOP close to the final reachable IOP value, based on the posttrabecular resistance, there is almost no additional reduction in $\mathrm{IOP}$, and the benefit is in the reduction of medications.

The reduction of medication burden differed according to the baseline IOP under pharmacological treatment. The percentage of eyes with medication reduction was lower for those with $\mathrm{IOP} \geq 18 \mathrm{mmHg}$ than $\mathrm{IOP}<18 \mathrm{mmHg}$ under pharmacological treatment (60.9\% vs. $84.2 \%$, respectively). More eyes in Group 1 did not completely need glaucoma medications at the end of follow-up than in Group 2 (79.0\% vs. $47.7 \%)$. This difference between pharmacologically controlled and uncontrolled eyes could be explained by the viability and function of posttrabecular structures (i.e., Schlemm's canal and collectors' channels). When posttrabecular structures are preserved and still functional, there is a greater chance that only bypassing the trabecular tissue will be sufficient for IOP control. Our results could represent additional indirect evidence that IOP control with pharmacological treatment can be used as a reasonable surrogate for posttrabecular status and function.

Although assessing a different trabecular device, but which also acts by bypassing the trabecular meshwork, Fea et al. found that in patients with preoperative IOP of $18 \mathrm{mmHg}$ or higher, the reduction in IOP and in the number of medications was higher ${ }^{(19)}$. The relationship between baseline IOP and the amount of IOP reduction is consistent in the literature, and we have also found that a higher baseline IOP is associated with higher reductions in IOP. However, outcomes concerning the relationship between the level of baseline IOP and the amount of medications reduction are contradictory. This could be related to differences in the study population and significant differences between the devices (size, mechanism of action, etc.).

As demonstrated in many previous studies, trabecular stenting procedures have a very good safety profile $e^{(14-16,20)}$. Most eyes showed improvement in visual acuity and were complication-free in both groups. No serious adverse events were observed during the follow-up.

Although the study population consisted of 170 eyes, the groups were not significantly similar in some important variables, such as baseline number of medications, glaucoma stage, and type of surgery (standalone or combined). These are important confounding variables, as they can also be a reflection of posttrabecular viability ${ }^{(11)}$. A smaller number of baseline medications, early glaucoma stages, and combined surgery are all related to a potentially better posttrabecular status ${ }^{(11)}$. Another possible confounding variable was the type of trabecu- 
lar bypass device. iStent and iStent inject have different designs and slightly different efficacy profiles ${ }^{(9,17,21)}$. After controlling for such variables in both univariate and multivariate regression analyses, the results were consistent and robust, confirming that IOP level under pharmacological therapy was a strong driver for our outcomes.

The strengths of our study include a large sample size $(n=170)$, long-term follow-up (6-38 months), a real-world setting, and a single center design. We also included both standalone and combined procedures, different glaucoma stages (mild to advanced stages), and first- and second-generation trabecular bypass devices.

However, our study had some limitations including its retrospective design. In addition, the majority of our patients were Caucasian, which limits the external validity of our findings. We have not controlled our study groups for medication adherence. This could have had an influence in our results, as some patients might have been included in group 2 (uncontrolled IOP) as non-respondent to medications, but the real issue could have been poor adherence. This confounding variable could have exacerbated the medication-free results in group 2, and we speculate that if we control for this important variable, the difference between groups would be even greater than we have found. When controlling for the number of baseline medications, we excluded patients on 1 medication. Results for patients under at least 2 medications might not be completely applicable for the patients on 1 medication, so one should be cautious when interpreting this attempt to control for such variables.

Further investigations, preferably in prospective and randomized clinical trials, are needed to confirm our findings.

In summary, both eyes with $\mathrm{IOP}<18 \mathrm{mmHg}$ and IOP $\geq 18 \mathrm{mmHg}$ under pharmacological treatment had high qualified success rates. However, eyes that were pharmacologically controlled at baseline $(\mathrm{IOP}<18 \mathrm{mmHg}$ under pharmacological treatment) showed higher long-term complete success rates and greater chances of achieving no need for glaucoma medications postoperatively.

\section{REFERENCES}

1. Saheb H, Ahmed II. Micro-invasive glaucoma surgery: current perspectives and future directions. Curr Opin Ophthalmol. 2012;23(2):96-104.

2. Pillunat LE, Erb C, Jünemann AG, Kimmich F. Micro-invasive glaucoma surgery (MIGS): a review of surgical procedures using stents. Clin Ophthalmol. 2017;11:1583-600.
3. Gillmann K, Mansouri K. Minimally Invasive glaucoma surgery: where is the evidence? Asia Pac J Ophthalmol (Phila). 2020; 9(3):203-14.

4. Andrew NH, Akkach S, Casson RJ. A review of aqueous outflow resistance and its relevance to microinvasive glaucoma surgery. Surv Ophthalmol. 2020;65(1):18-31.

5. Huang AS, Saraswathy S, Dastiridou A, Begian A, Mohindroo C, Tan JC, et al. Aqueous angiography-mediated guidance of trabecular bypass improves angiographic outflow in human enucleated eyes. Invest Ophthalmol Vis Sci. 2016;57(11):4558-65.

6. Buffault J, Labbé A, Hamard P, Brignole-Baudouin F, Baudouin C. The trabecular meshwork: Structure, function and clinical implications. A review of the literature. J Fr Ophtalmol. 2020;43(7):e217-30.

7. Craven ER. Trabecular micro-bypass shunt (iStent ${ }^{\circledR}$ ): basic science, clinical, and future). Middle East Afr J Ophthalmol. 2015;22(1):30-7.

8. Hill RA, Haffner D, Voskanyan L. The iStent ${ }^{\circledR}$ MIGS family: IStent ${ }^{\circledR}$, iStent Inject ${ }^{\circledast}$, and iStent Supra. Surgical Innovations in Glaucoma. Vol. Springer New York; 2014. p. 147-56.

9. 9. Resende AF, Patel NS, Waisbourd M, Katz LJ. iStent ${ }^{\circledR}$ trabecular microbypass stent: an update. J Ophthalmol. 2016;2016:2731856.

10. Chansangpetch S, Ittarat M, Yang S, Fisher AC, Singh K, Lin SC, et al. Comparison of 1-year effectiveness of trabecular microbypass stent implantation (istent) in conjunction with phacoemulsification among mild, moderate, and severe primary open-angle glaucoma patients. J Glaucoma. 2020;29(7):542-9.

11. Paletta Guedes RA, Gravina DM, Paletta Guedes VM, Chaoubah A. Factors associated with unqualified success after trabecular bypass surgery. a case-control study. J Glaucoma. 2020; 29(11):1082-7.

12. Konopińska J, Kozera M, Kraśnicki P, Mariak Z, Rẹkas M. The Effectiveness of First-Generation iStent Microbypass Implantation Depends on Initial Intraocular Pressure: 24-Month Follow-Up Prospective Clinical Trial. J Ophthalmol. 2020.

13. Perkins TW. Clinical decisions in glaucoma. Arch Ophthalmol. 1994;112(12):1518-9.

14. Lavia C, Dallorto L, Maule M, Ceccarelli M, Fea AM. Minimally-invasive glaucoma surgeries (MIGS) for open angle glaucoma: A systematic review and meta-analysis. PLoS One. 2017;12(8):e0183142.

15. Samuelson TW, Katz LJ, Wells JM, Duh YJ, Giamporcaro JE; US iStent Study Group. Randomized evaluation of the trabecular micro-bypass stent with phacoemulsification in patients with glaucoma and cataract. Ophthalmology. 2011;118(3):459-67.

16. Samuelson TW, Sarkisian SR Jr, Lubeck DM, Stiles MC, Duh YJ, Romo EA, et al.; iStent Inject Study Group. Prospective, randomized, controlled pivotal trial of an ab interno implanted trabecular micro-bypass in primary open-angle glaucoma and cataract: two-year results. Ophthalmology. 2019;126(6):811-21.

17. Guedes RA, Gravina DM, Lake JC, Guedes VM, Chaoubah A. One-year comparative evaluation of iStent or iStent inject implantation combined with cataract surgery in a single center. Adv Ther. 2019;36(10):2797-810.

18. 18. Ferguson TJ, Berdahl JP, Schweitzer JA, Sudhagoni RG. Clinical evaluation of a trabecular microbypass stent with phacoemulsification in patients with open-angle glaucoma and cataract. Clin Ophthalmol. 2016;10:1767-73.

19. Fea AM, Rekas M, Au L. Evaluation of a Schlemm canal scaffold microstent combined with phacoemulsification in routine clinical practice: two-year multicenter study. J Cataract Refract Surg. 2017;43(7):886-91.

20. Le K, Saheb H. iStent trabecular micro-bypass stent for open-angle glaucoma. Clin Ophthalmol. 2014;8:1937-45.

21. 21. Guedes RA, Gravina DM, Lake JC, Guedes VM, Chaoubah A. Intermediate results of iStent or iStent inject implantation combined with cataract surgery in a real-world setting: A longitudinal retrospective study. Ophthalmol Ther. 2019;8(1):87-100. 